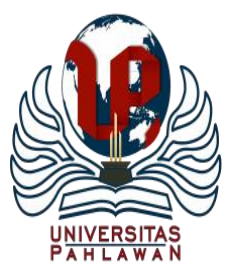

Jurnal Abdidas Volume 2 Nomor 1 Tahun 2021 Halaman 11-15

JURNAL ABDIDAS

http://abdidas.org/index.php/abdidas

\title{
Pentingnya Antenatal Care (ANC) di Fasilitas Pelayanan Kesehatan oleh Tenaga Kesehatan di Desa Penyengat Olak Kecamatan Jambi Luar Kota Kabupaten Muaro Jambi
}

\author{
Herinawati $^{1 \bowtie}$, Iksaruddin ${ }^{2}$, Ika Murtiyarini ${ }^{3}$, Atika Fadhilah Danaz Nst ${ }^{4}$ \\ Kebidanan, Poltekkes Kemenkes Jambi, Indonesia ${ }^{1,3,4}$ \\ Promkes, Poltekkes Kemenkes Jambi, Indonesia ${ }^{2}$ \\ E-mail: herinawati burhanuddin@yahoo.com ${ }^{1}, \underline{\text { iksancbflamboyan@gmail.com }}^{2}$, ika.murtiyarini@gmail.com ${ }^{3}$, \\ atika.guntara@gmail.com ${ }^{4}$
}

\begin{abstract}
Abstrak
Pemeriksaan kehamilan atau Antenatal Care (ANC) merupakan asuhan yang diberikan saat hamil sampai sebelum melahirkan. ANC penting untuk menjamin agar proses alamiah tetap berjalan normal dan mendeteksi ibu hamil yang tidak normal sehingga komplikasi yang mungkin terjadi selama kehamilan dapat terdeteksi secara dini serta ditangani secara memadai. Kegiatan pengabdian masyarakat berupa penyuluhan tentang pentingnya Antenatal Care (ANC) di fasilitas pelayanan kesehatan oleh tenaga kesehatan dan pemeriksaan kehamilan di Puskesmas Penyengat Olak, Kecamatan Jambi Luar Kota, Kabupaten Muaro Jambi dihadiri oleh 50 peserta terdiri dari ibu hamil, kader kesehatan, tenaga kesehatan dan tokoh masyarakat. Semua tenaga kesehatan khususnya bidan lebih aktif mempromosikan tentang Pentingnya Antenatal Care (ANC) di fasilitas pelayanan kesehatan oleh tenaga kesehatan di Desa penyengat Olak, Kecamatan Jambi Luar Kota, Kabupaten Muaro Jambi. Hasil yang dicapai dalam pengabdian pada masyarakat ini adalah peningkatan pengetahuan ibuibu hamil, kader kesehatan dan tokoh masyarakat, pentingnya Antenatal Care (ANC) di fasilitas pelayanan kesehatan oleh tenaga kesehatan, melakukan pemeriksaan Antenatal Care (ANC) di fasilitas pelayanan kesehatan oleh tenaga kesehatan.
\end{abstract}

Kata kunci: antenatal care, kehamilan, tanda bahaya, tenaga kesehatan

\section{Abstract}

Antenatal Care (ANC) is the care given during pregnancy to before delivery. ANC is important to ensure that natural processes continue to run normally and detect abnormal pregnant women so that complications that may occur during pregnancy can be detected early and handled adequately. Community service activities in the form of counseling on the importance of antenatal care (ANC) in health service facilities by health workers and pregnancy checks at the Penyengat Olak Community Health Center, Jambi Outer City District, Muaro Jambi Regency was attended by 50 participants consisting of pregnant women, health cadres, health workers and figures Public. All health workers, especially midwives, are more active in promoting the importance of Ante Natal Care $(A N C)$ in health service facilities by health workers in Penyengat Olak Village, Jambi District, Muaro Jambi District. The results achieved in this community service are increased knowledge of pregnant women, health cadres and community leaders, the importance of antenatal care (ANC) in health care facilities by health personnel, conducting Antenatal Care (ANC) checks at health service facilities health workers.

Keywords: antenatal care, hazard signs, health workers, pregnancy

Copyright (c) 2021 Herinawati, Iksaruddin, Ika Murtiyarini, Atika Fadhilah Danaz Nst

$\triangle$ Corresponding author

Address : Poltekkes Kemenkes Jambi

Email : herinawati burhanuddin@yahoo.com

DOI $\quad:$ https://doi.org/10.31004/abdidas.v2i1.187

ISSN 2721- 9224 (Media Cetak)

ISSN 2721- 9216 (Media Online) 


\section{PENDAHULUAN}

Pemeriksaan kehamilan atau Antenatal Care (ANC) merupakan asuhan yang diberikan saat hamil sampai sebelum melahirkan. ANC penting untuk menjamin agar proses alamiah tetap berjalan normal dan mendeteksi ibu hamil yang tidak normal sehingga komplikasi yang mungkin terjadi selama kehamilan dapat terdeteksi secara dini serta ditangani secara memadai (Kemenkes, 2013). Apabila ibu hamil tidak melakukan pemeriksaan kehamilan, maka tidak akan diketahui apakah kehamilannya berjalan dengan baik atau mengalami keadaan risiko tinggi dan komplikasi obstetrik yang dapat membahayakan kehidupan ibu atau janinnya (Prawiharjo, 2014).

Menurut Survei Demografi Kesehatan Indonesia (SDKI), Angka kematian Ibu (AKI) di Indonesia pada tahun 2018 adalah 248 per 100.000 kelahiran hidup. Angka ini sudah lebih rendah daripada survei sebelumnya yaitu 307 per 100.000 kelahiran hidup pada tahun 2013, namun masih merupakan yang tertinggi di kawasan Asia Tenggara. Angka Kematian Bayi (AKB) tahun 2018 dari 35 per 1000 kelahiran hidup menjadi 34 per 1000 kelahiran hidup pada tahun 2013 (Kemenkes RI, 2018).

Angka Kematian Ibu (AKI) merupakan salah satu indikator dari tingkat kesehatan suatu daerah. Dengan kata lain, tingginya angka kematian ibu, menunjukkan rendahnya tingkat kesehatan di daerah tersebut (Prawiroharjo, 2014). Pelayanan kesehatan ibu selama kehamilan merupakan hal penting bagi ibu hamil maupun bayi yang dikandungnya. Upaya pelayanan tersebut merupakan salah satu upaya pencegahan terhadap kondisi buruk yang dapat terjadi pada seorang ibu hamil. Berbagai kondisi dapat terjadi pada seorang ibu hamil. Berbagai kondisi dapat terjadi pada seorang ibu hamil. Adapun kondisi paling buruk yang dapat terjadi pada seorang ibu hamil adalah kematian (Salmah, 2012).

Kematian ibu hamil dan bersalin dipengaruhi oleh beberapa faktor yaitu pendidikan dan pengetahuan, sosial budaya, sosial ekonomi, geografi dan lingkungan, aksesabilitas ibu pada fasilitas kesehatan serta kebijakan makro dalam kualitas pelayanan kesehatan (Saifuddin, 2012). Adapun penyebab dasar kematian ibu, dapat digunakan model 3 terlambat yang terdiri dari: 1) terlambat mengenal bahaya dan mengambil keputusan merujuk ke fasilitas kesehatan; 2) terlambat mencapai fasilitas pelayanan rujukan; dan; 3) terlambat memperoleh pelayanan adekuat di fasilitas rujukan. Berkaitan dengan model 3 terlambat tersebut, terdapat perbedaan distribusi dari masing-masing faktor penyebab kematian ibu. Perdarahan merupakan penyebab kematian tertinggi, yaitu sebanyak 28\%. Persentase tertinggi kedua disebabkan oleh eklampsia, yaitu sebanyak 24\%. Sebab-sebab lainnya antara lain infeksi $(14,9 \%)$, abortus $(12,9 \%)$, partus lama $(6,9 \%)$, emboli $(2,1 \%)$, serta komplikasi pasca persalinan (9,2\%). Memperhatikan beberapa faktor tersebut, maka berbagai upaya pencegahan terjadinya kematian pada ibu dapat dilakukan. Penyediaan pelayanan antenatal care yang memadai merupakan upaya pencegahan kematian ibu hamil (Manuaba, 2012). 


\section{Pemeriksaan Antenatal Care (ANC)}

merupakan pemeriksaan kehamilan yang bertujuan untuk meningkatkan kesehatan fisik dan mental pada ibu hamil secara optimal, hingga mampu menghadapi masa persalinan, nifas, menghadapi persiapan pemberian ASI secara eksklusif, serta kembalinya kesehatan alat reproduksi dengan wajar (Kemenkes RI, 2012). Pemeriksaan kehamilan dilakukan minimal 4 (empat) kali selama masa kehamilan, yaitu 1 kali pemeriksaan pada trimester pertama, 1 kali pemeriksaan pada trimester kedua, dan 2 kali pemeriksaan pada trimester (Amiruddin, 2014).

Salah satu upaya untuk menurunkan AKI adalah dengan melakukan pemeriksaan kehamilan yang sesuai dengan Standar Operasional Prosedur (SOP) yaitu pada standar minimal 7T (timbang berat badan, ukur tekanan darah, ukur tinggi fundus uteri, imunisasi tetanus toxoid, pemberian tablet besi, tes terhadap penyakit menular seksual, temu wicara) dalam pelayanan program antenatal ibu hamil. Jika standar pelayanan dilaksanakan sudah sesuai diharapkan dapat mendeteksi risiko tinggi pada ibu hamil lebih awal dan dapat dilakukan rujukan sesegera mungkin (Kemenkes RI, 2013a).

Di Desa Penyengat Olak, Kecamatan Jambi Luar Kota, Kabupaten Muaro Jambi berdasarkan survei awal masih ada ibu hamil yang memeriksakan kehamilan bukan dengan tenaga kesehatan. Tujuan kegiatan ini untuk memberikan informasi dan pengetahuan kepada ibu hamil mengenai pentingnya memeriksakan kehamilan pada tenaga kesehatan, khususnya bidan.

\section{METODE}

Kegiatan pengabdian masyarakat ini di laksanakan setiap hari Sabtu, pukul 09.00-12.00 WIB di Desa Penyengat Olak, Kecamatan Jambi Luar Kota. Adapun metode dan bentuk kegiatan ini adalah penyuluhan, diskusi dan tanya jawab. dihadiri oleh 50 peserta terdiri dari ibu hamil, kader kesehatan, tenaga kesehatan dan tokoh masyarakat. Daftar hadir peserta pada kegiatan dan dokumentasi serta materi penyuluhan berupa buku saku dengan judul pentingnya Antenatal Care (ANC) di fasilitas pelayanan kesehatan oleh tenaga kesehatan ada pada lampiran.

Kegiatan ini menggunakan buku saku yang menjelaskan mengenai pentingnya Antenatal Care (ANC) di fasilitas pelayanan kesehatan oleh tenaga kesehatan, melakukan pemeriksaan kehamilan di fasilitas pelayanan kesehatan oleh tenaga kesehatan dan pemberian buku saku. Sarana dan prasarana yang dipakai untuk melaksanakan kegiatan ini adalah alat tulis, buku saku, alat periksa kehamilan, ruangan yang nyaman, tempat tidur lengkap, metlin, dopler, reflek hammer dan jangka panggul.

\section{HASIL DAN PEMBAHASAN}

Kegiatan pengabdian dilakukan bulan Juli 2019 dengan melakukan penyuluhan tentang pentingnya Antenatal Care (ANC) di fasilitas pelayanan kesehatan oleh tenaga kesehatan. Adapun tahapan pengabdian masyarkat ini adalah melakukan kegiatan sosialisasi dengan kepala puskesmas dan staf tentang kegiatan promosi kesehatan pentingnya Antenatal Care (ANC) di 
fasilitas pelayanan kesehatan oleh tenaga kesehatan, pengidentifikasian ibu hamil calon peserta, promosi kesehatan pentingnya Antenatal Care (ANC) di fasilitas pelayanan kesehatan oleh tenaga kesehatan, melakukan pemeriksaan kehamilan di fasilitas pelayanan kesehatan oleh tenaga kesehatan, dan evaluasi monitoring.

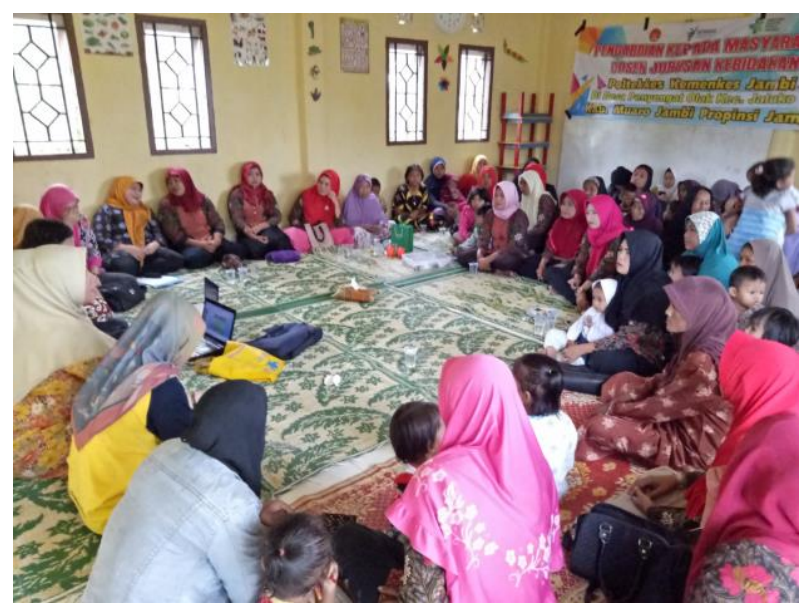

Gambar 1. Penyuluhan Tentang Pentingnya Pemeriksaan Kehamilan

Penyuluhan dilakukan setelah pretest. Penyuluhan diawali dengan pembukaan sambutan oleh Kepala Puskesmas Penyengat Olak dilanjutkan perkenalan kemudian penyampaian materi. Penyuluhan tentang pentingnya Antenatal Care (ANC) di fasilitas pelayanan kesehatan oleh tenaga kesehatan. Dengan metode presentasi menggunakan media power point dan video yang ditampilkan melalui layar LCD. Setelah materi selesai disampaikan, dilanjutkan dengan diskusi dan praktik langsung oleh para kader. Selama penyuluhan, pada kader di Puskesmas Penyengat Olak sangat antusias selanjutnya dilakukan posttest.
Dari hasil pretest dan post-test ternyata ada peningkatan secara signifikan. Pendampingan dan pelatihan secara langsung meningkatkan pengetahuan juga menjadi capaian kegiatan pengabdian masyarakat. Hal ini juga dapat dilihat dari perubahan hasil pretest dan post-test yang sudah dilakukan sebelum dan sesudah pemberian edukasi dan sosialisasi, dimana pemberian soal pretest dan post-test ini untuk mengetahui sejauh mana keberhasilan pemberian pendidikan kesehatan (penyuluhan) terhadap ibu hamil dan para kader.

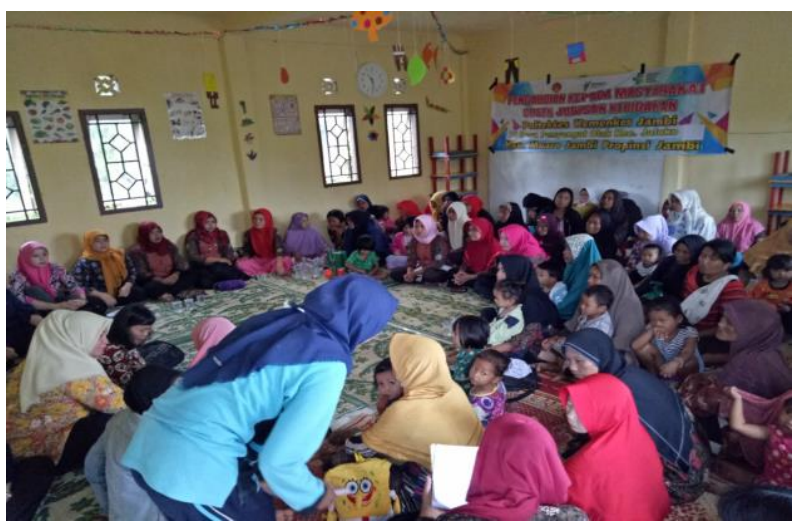

Gambar 2. Peserta yang Hadir Aktif Bertanya

Peran petugas kesehatan sangat signifikan untuk mensosialisasikan pentingnya melakukan Antenatal Care (ANC) pada masa kehamilan terhadap keluarga terutama suami agar memberikan kunjungan Antenatal Care (ANC). Hal ini sejalan dengan penelitian Nirmala (2014) bahwa ibu hamil yang mendapat dukungan tenaga kesehatan mempunyai peluang sebesar 7,4 kali untuk melakukan kunjungan ANC secara lengkap dibandingkan dengan ibu hamil yang tidak mendapat dukungan tenaga kesehatan. 
Hasil yang dicapai dalam pengabdian pada masyarakat ini adalah peningkatan pengetahuan ibu-ibu hamil, kader kesehatan dan tokoh masyarakat, pentingnya Antenatal Care (ANC) di fasilitas pelayanan kesehatan oleh tenaga kesehatan, melakukan pemeriksaan Antenatal Care (ANC) di fasilitas pelayanan kesehatan oleh tenaga kesehatan.

\section{SIMPULAN}

Adapun kesimpulan dalam kegiatan pengabdian masyarakat ini adalah meningkatnya pengetahuan ibu-ibu hamil, kader kesehatan dan tokoh masyarakat tentang pentingnya Antenatal Care (ANC) di fasilitas pelayanan kesehatan oleh tenaga kesehatan di Puskesmas Penyengat Olak, Kecamatan Jambi Luar Kota, Kabupaten Muaro Jambi, telah dilakukan pemeriksaan Antenatal Care (ANC) di fasilitas pelayanan kesehatan oleh tenaga kesehatan di Puskesmas Penyengat Olak, Kecamatan Jambi Luar Kota, Kabupaten Muaro Jambi.

\section{UCAPAN TERIMA KASIH}

Penulis mengucapkan terimakasih kepada Politeknik Kesehatan Kemenkes Jambi yang telah memberikan kesempatan untuk melaksanakan salah satu Tri Dharma Perguruan Tinggi yakni pengabdian kepada masyarakat, kepada Puskesmas Penyengat Olak atas kesediaannya sebagai tempat pengabdian dan kepada ibu hamil yang telah berpartisipasi dalam kegiatan ini.

\section{DAFTAR PUSTAKA}

Amiruddin, R. \& H. (2014) Determinan Kesehatan Ibu dan Anak. Jakarta: Trans Info Media.

Kemenkes RI (2012) Standar Pelayanan Kebidanan. Jakarta: Departemen Kesehatan RI.

Kemenkes RI (2013) Pedoman Pelayanan Antenatal. Jakarta: Direktorat jendral bina pelayanan medik.

Kemenkes RI (2013) Standar Pelayanan Kesehatan Kehamilan. Jakarta: Departemen Kesehatan RI.

Kemenkes RI (2018) Profil Kesehatan Indonesia 2018. Jakarta: Kemenkenkes RI.

Manuaba. Ida Bagus (2012) Ilmu Kebidanan Penyakit Kandungan dan KB Untuk Pendidikan Bidan. 2nd edn. Jakarta: EGC.

Prawiharjo, S. (2014) Pelayanan Kesehatan Maternal dan Neonatal. Jakarta: Yayasan Bina Pustaka Sarwono Prawiroharjo.

Prawiroharjo, S. (2014) Ilmu Kebidanan. Jakarta: Yayasan Bina Pustaka Sarwono Prawiroharjo.

Saifuddin, A. (2012) Buku Panduan Praktis Pelayanan Kesehatan Maternal dan Neonatal Yayasan Bina Pustaka. Jakarta: Yayasan Bina Pustaka.

Salmah, Rusmiati, Maryanah, Susanti, N. . (2012) Asuhan Kebidanan Antental. Jakarta: EGC. 